\title{
BMJ Open The association between insulin therapy and depression in patients with type 2 diabetes mellitus: a meta-analysis
}

To cite: Bai X, Liu Z, Li Z, et al. The association between insulin therapy and depression in patients with type 2 diabetes mellitus: a meta-analysis. BMJ Open 2018;8:e020062. doi:10.1136/ bmjopen-2017-020062

- Prepublication history and additional material for this paper are available online. To view please visit the journal online (http://dx.doi.org/10.1136/ bmjopen-2017-020062)

Received 11 October 2017 Revised 12 September 2018 Accepted 25 September 2018

Check for updates

(C) Author(s) (or their employer(s)) 2018. Re-use permitted under CC BY-NC. No commercial re-use. See rights and permissions. Published by BMJ.

${ }^{1}$ Department of Endocrinology, People's Hospital of Longhua, Shenzhen, China

${ }^{2}$ Department of Endocrinology, The Second People's Hospital of Shenzhen, Shenzhen, China

Correspondence to

Dr Xiaosu Bai; bxsllb@163.com

\section{ABSTRACT}

Objectives Several patients with type 2 diabetes mellitus (T2DM) have depressive disorders. Whether insulin treatment was associated with increased risk of depression remains controversial. We performed a metaanalysis to evaluate the association of insulin therapy and depression.

Design A meta-analysis.

Methods We conducted a systematic search of PubMed, PsycINF0, Embase and the Cochrane Library from their inception to April 2016. Epidemiological studies comparing the prevalence of depression between insulin users and non-insulin users were included. A random-effects model was used for meta-analysis. The adjusted and crude data were analysed.

Results Twenty-eight studies were included. Of these, 12 studies presented with adjusted ORs. Insulin therapy was significantly associated with increased risk of depression $(\mathrm{OR}=1.41,95 \% \mathrm{Cl} 1.13$ to $1.76, \mathrm{p}=0.003)$. Twenty-four studies provided crude data. Insulin therapy was also associated with an odds for developing depression ( $0 \mathrm{R}=1.59,95 \% \mathrm{Cl} 1.41$ to $1.80, \mathrm{p}<0.001)$. When comparing insulin therapy with oral antidiabetic drugs, significant association was observed for adjusted $(\mathrm{OR}=1.42,95 \% \mathrm{Cl} 1.08$ to $1.86, \mathrm{p}=0.008)$ and crude $(0 \mathrm{R}=1.61,95 \% \mathrm{Cl} 1.35$ to $1.93, \mathrm{p}<0.001)$ data.

Conclusions Our meta-analysis confirmed that patients on insulin therapy were significantly associated with the risk of depressive symptoms.

\section{INTRODUCTION}

Diabetes and depression are major global public health problems, and both of these are likely to be among the five leading causes of disease burden by $2030 .{ }^{1}$ Approximately $90 \%$ of diabetic patients was type 2 diabetes (T2DM). ${ }^{2}$ Recently, a bidirectional link between T2DM and depression has been recognised. ${ }^{3}$ According to a meta-analysis study, depression was associated with $60 \%$ increased risk of T2DM. ${ }^{4}$ Meanwhile, T2DM was associated with $24 \%$ increased risk of depressive symptoms. ${ }^{5}$ Further, depression adversely affects the prognosis and reduces the patient's quality of life. ${ }^{67}$ Growing evidence has shown that T2DM and depression may share similar lifestyle factors and biological origins. ${ }^{3}$

\section{Strengths and limitations of this study}

The primary strength of this study was the systematic and expansive search of multiple databases which minimised the risk of missing data.

- Both the adjusted and crude effect estimates were analysed and demonstrated consistent results.

- Our findings mainly relied on cross-sectional data; and as such could not establish the causal and temporal relationships between insulin use and depression.

- Some studies had small sample sizes, which may influence the statistical power.

- The findings of insulin therapy versus specific oral drugs and the prevalence of depression were not illustrated because of the inclusion of a less number of studies in each subset.

T2DM is a chronic and progressive disease characterised by insulin resistance and dysfunction of pancreatic islet $\beta$ cells. ${ }^{8}$ For patients with T2DM, insulin is the cornerstone of treatment for lowering glucose and glycated hemoglobin (HbA1c) concentrations. ${ }^{10}$ Although the optimal timing and indications for insulin therapy remain controversial, $^{11-13}$ most of the patients inevitably require insulin therapy to attain adequate glycaemic control in the natural history of T2DM. $^{1114}$

However, insulin treatment seems to be less popular than oral hypoglycaemic medications. Approximately $25 \%$ of the patients with T2DM are reluctant to take insulin as the 'last-resort' option. ${ }^{15}$ Some patients may experience considerable psychological disorders with the transition from oral antidiabetic drugs to insulin. Additionally, depressive symptoms were more commonly seen in patients who undergo more frequent insulin injections per day. ${ }^{16}$ However, the correlations between insulin use and depression among previous studies were inconsistent. Several studies have demonstrated a positive correlation, ${ }^{17-19}$ whereas other studies have the opposite result. ${ }^{20-22}$ Besides, these 
studies varied in the enrolled population, adjustment of confounding factors and usage of depression assessment tools. Thus, we conducted a systematic review and meta-analysis to clarify the association between insulin therapy and the development of depression in patients with T2DM.

\section{METHODS}

\section{Patient and public involvement}

No patients were involved in the study design or conduct of the study.

\section{Search strategy}

This study is reported in accordance with the Meta-analysis Of Observational Studies in Epidemiology guidelines. ${ }^{23}$ We conducted a systematic computerised search of Pubmed, Ovid PsycINFO, Embase, and the Cochrane Library for eligible studies from their inception to April 2016. The following keywords and medical subject headings were used for the search: (depression OR depressive) AND (diabetes OR diabetic) AND insulin AND (cross-sectional OR population-based OR cohort OR prospective OR retrospective OR prevalence OR survey OR database OR trial). The full search strategy for Pubmed is shown in online supplementary file. The language was restricted to English. We also manually screened the reference lists of selected studies to obtain potentially relevant records.

\section{Inclusion and exclusion criteria}

We included studies that: (1) Investigated the development of depression in insulin users and non-insulin users (oral antidiabetic drug, diet or no treatment) among patients with T2DM. (2) Reported adjusted/unadjusted ORs or risk ratios (RRs), or presented raw data that could produce crude effect estimates. (3) Assessed depression by self-report measures or diagnostic interviews. The self-report scales including the Patient Health Questionnaire (PHQ), Beck Depression Inventory and the Centre for Epidemiologic Studies-Depression Scale were used. ${ }^{24}$ The diagnostic interviews were based on the criteria of Diagnostic and Statistical Manual of Mental Disorders (DSM) or International Classification of Diseases (ICD) ${ }^{25}{ }^{26} \mathrm{~A}$ threshold score was not defined as no consensus was available and the threshold varied in different clinical settings. Studies were excluded if: (1) T2DM was mixed with type 1 diabetes. (2) Comparison was conducted between patients with T2DM and patients without T2DM. (3) Depression could not be distinguished from anxiety or distress. (4) ORs or RRs could not be obtained or calculated, for example, we excluded studies that reported only mean and SD of outcome measures.

\section{Data collection and quality assessment}

Two reviewers independently screened the titles and abstracts of eligible studies and extracted the data. Any disagreement was resolved by consensus. The following study characteristics were extracted: author, publication year, study design, country, sample size, mean or median age, proportion of men, depression diagnostic criteria, compared groups and adjustment of effect estimates. The unadjusted and adjusted effect estimates and 95\% CIs were directly extracted or indirectly calculated. The degree of adjustment for confounders were categorised as: ' + ' for age and/or sex only; ' ++ ' for those with further adjusted for more than two standard sociobehavioural risk factors (ie, education, race, marital status, insurance, exercise, occupation, smoking status, alcohol consumption, family history of diabetes and body mass index); ' +++' for those with +2 or more clinical factors, including dyslipidaemia, hypertension, cardiovascular disease, duration of T2DM, HbA1c level, treatment intensity and diabetic complications. The quality was assessed by the modified Newcastle-Ottawa Scale (NOS). ${ }^{27}$ This scale awarded a maximum of 8 points to each study, with $\leq 6$ points indicating a high risk of bias.

\section{Statistical analysis}

As most of the included studies were cross-sectional, effect sizes were expressed as ORs. Given the low prevalence of depression in patients with T2DM, the RR reported by prospective study approximated the OR. Where available, the fully adjusted OR was pooled into meta-analysis to avoid the bias caused by confounding factors. However, the degree of adjustment and the variables entering into regression models varied between the included studies. Thus, we additionally pooled the unadjusted ORs for data homogeneity. The random-effects model was used for meta-analysis. Heterogeneity was assessed by Cochran's $Q$ statistics and $\mathrm{I}^{2}$ values. A value of $p<0.05$ was regarded as significant heterogeneity for $Q$ test. $\mathrm{I}^{2}$ ranged between $0 \%$ (no heterogeneity) and $100 \%$ (high heterogeneity), with values around 25\%, $50 \%$ and $75 \%$ suggesting low, moderate and high heterogeneity, respectively. ${ }^{28}$ To weigh up the relative influence of each individual study, sensitivity analysis was performed by excluding one study at a time and assessing the alteration in pooled results. Subgroup analyses and meta-regression analyses were performed using the following variables: compared groups (insulin vs non-drug therapy or insulin vs oral antidiabetic drugs), degree of adjustment of confounders $(+,++$ or +++ ), region (USA, Asia, Europe or Africa), identification of depression (self-report questionnaire or medical records), sample size $(\geq 1000$ or $<1000)$, mean age $(\geq 60$ or $<60)$, percentage male $(\geq 50$ or $<50)$ and NOS $(7 / 8$ or $<7)$. Publication bias was assessed by Egger's and Begg's tests, with $\mathrm{p}<0.05$ indicating significant asymmetry. ${ }^{29}{ }^{30}$ Also, we visually inspected the funnel plot for publication bias. All analyses were conducted by the Stata software (V.12.0; StataCorp, College Station, Texas, USA). A p value $<0.05$ was considered to be statistically significant.

\section{RESULTS}

\section{Study selection}

A total of 2102 records were identified including 595 articles from Pubmed, 836 articles from PsycINFO, 359 articles from Embase and 312 articles from Cochrane 


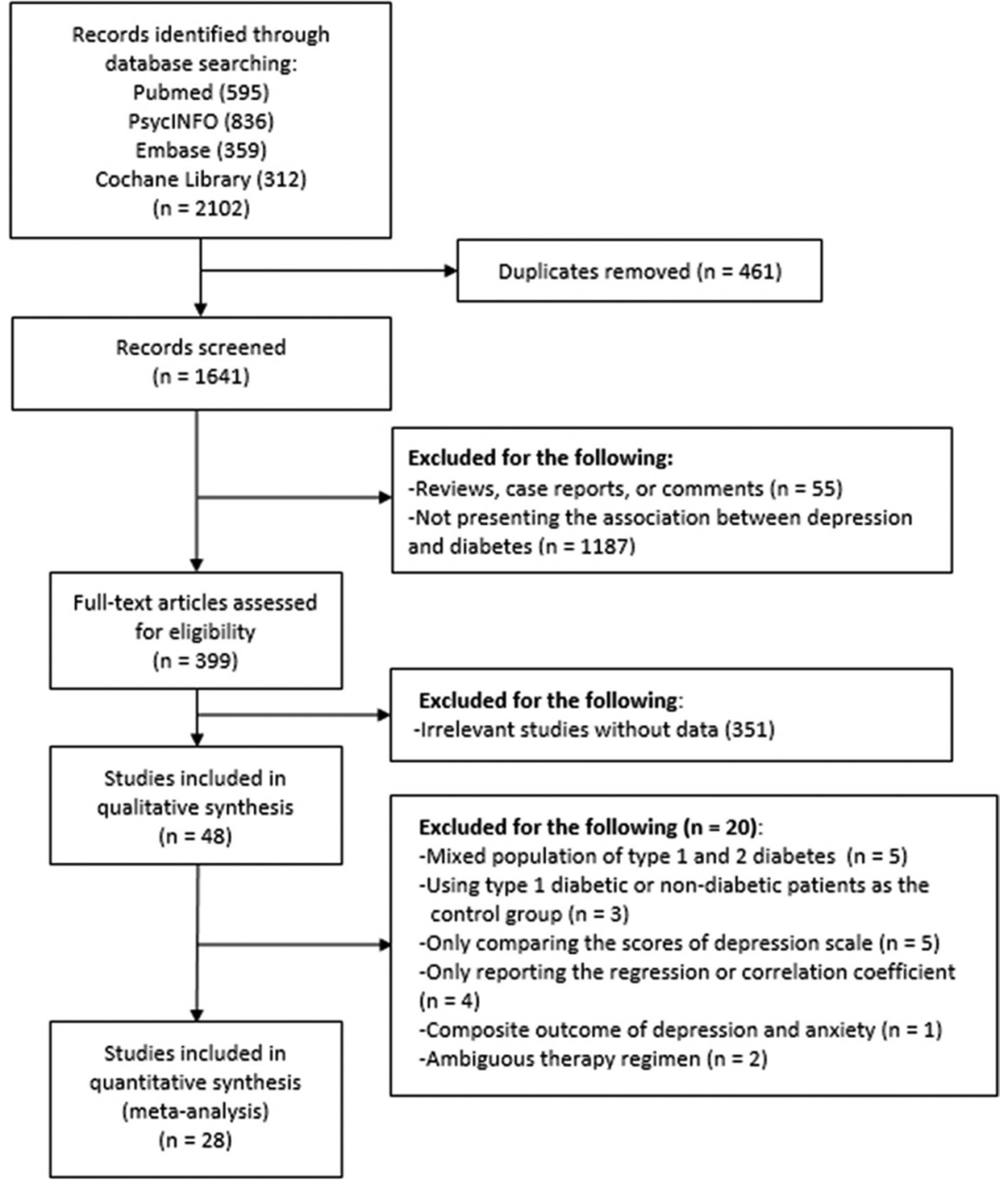

Figure 1 The selection process for eligible studies.

Library. We removed 461 duplicates. Further, 399 fulltext articles were assessed for eligibility. After excluding 353 records with insufficient or irrelevant data, 46 studies were included into qualitative synthesis. We excluded five studies enrolling mixed patients with type 1 diabetes and patients with T2DM, three studies comparing depression between DM and non-DM patients, four studies comparing the mean or median scores of depression questionnaire, four studies reporting the regression or correlation coefficient, one study presenting a mixed outcome of depression and anxiety, and two studies reporting a mixed treatment regimen of insulin or oral drugs. Finally, 28 studies were included into the meta-analysis. The flow diagram was shown in figure 1 .

\section{Study characteristics and quality assessment}

Except for 1 prospective cohort study, ${ }^{31}$ most of the 28 studies pooled in the meta-analysis were cross-sectional. A worldwide distribution was displayed, including 5 US studies, 8 European studies, 10 Asian studies, 2 African studies, 1 South-American study, and 1 study of a mixed
South-American and European population. The sample size ranged from 90 to 229047 . The prevalence of depression ranged from $3.4 \%$ to $51.1 \%$. Seven studies reported both the adjusted and unadjusted ORs, ${ }^{17} 2021$ 32-35 five studies reported adjusted ORs, ${ }^{3136-39}$ and unadjusted ORs were retrieved from 16 studies. ${ }^{18}{ }^{40-54}$ Descriptive data of the included studies are summarised in table 1 . In quality assessment, all studies had low to moderate risk of bias, with scores ranging from 6 to 8 . The items least satisfied were the control of confounding factors $(12 / 28)$ and the report of response rates or follow-up data $(10 / 28)$, (table 2).

\section{Meta-analysis of adjusted data}

The adjusted ORs for comparison of depression between insulin-treated and non-insulin-treated patients were reported by 12 studies. Compared with non-insulin treatment, insulin therapy was associated with a significantly higher risk of depression (OR=1.41, 95\% CI 1.13 to 1.76 , $\mathrm{p}=0.003$ ). Significantly high heterogeneity was revealed $\left(\mathrm{I}^{2}=69.7 \%, \mathrm{p}<0.001\right)$ (figure 2$)$. 


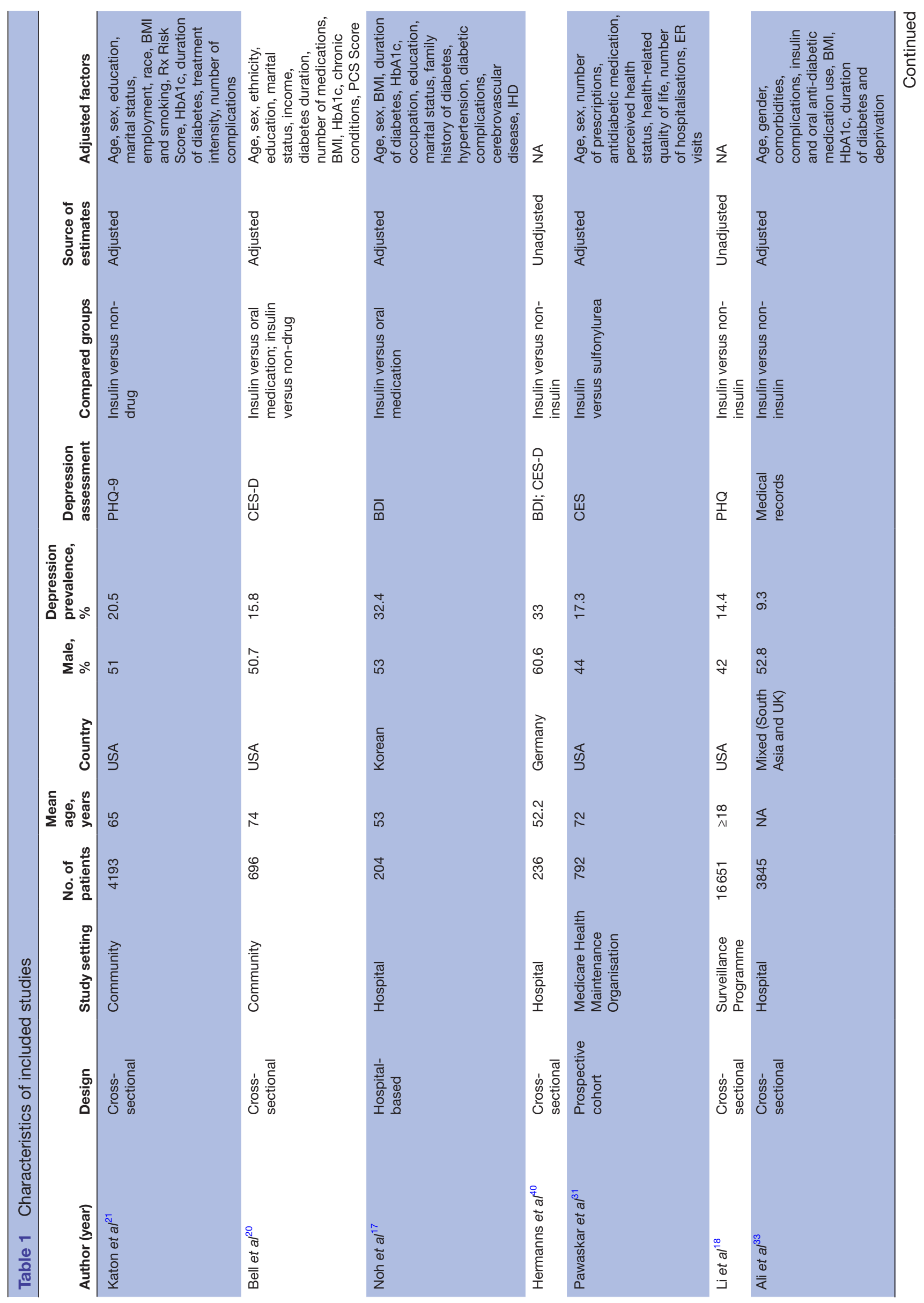

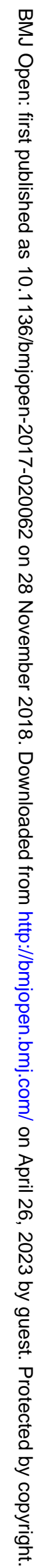




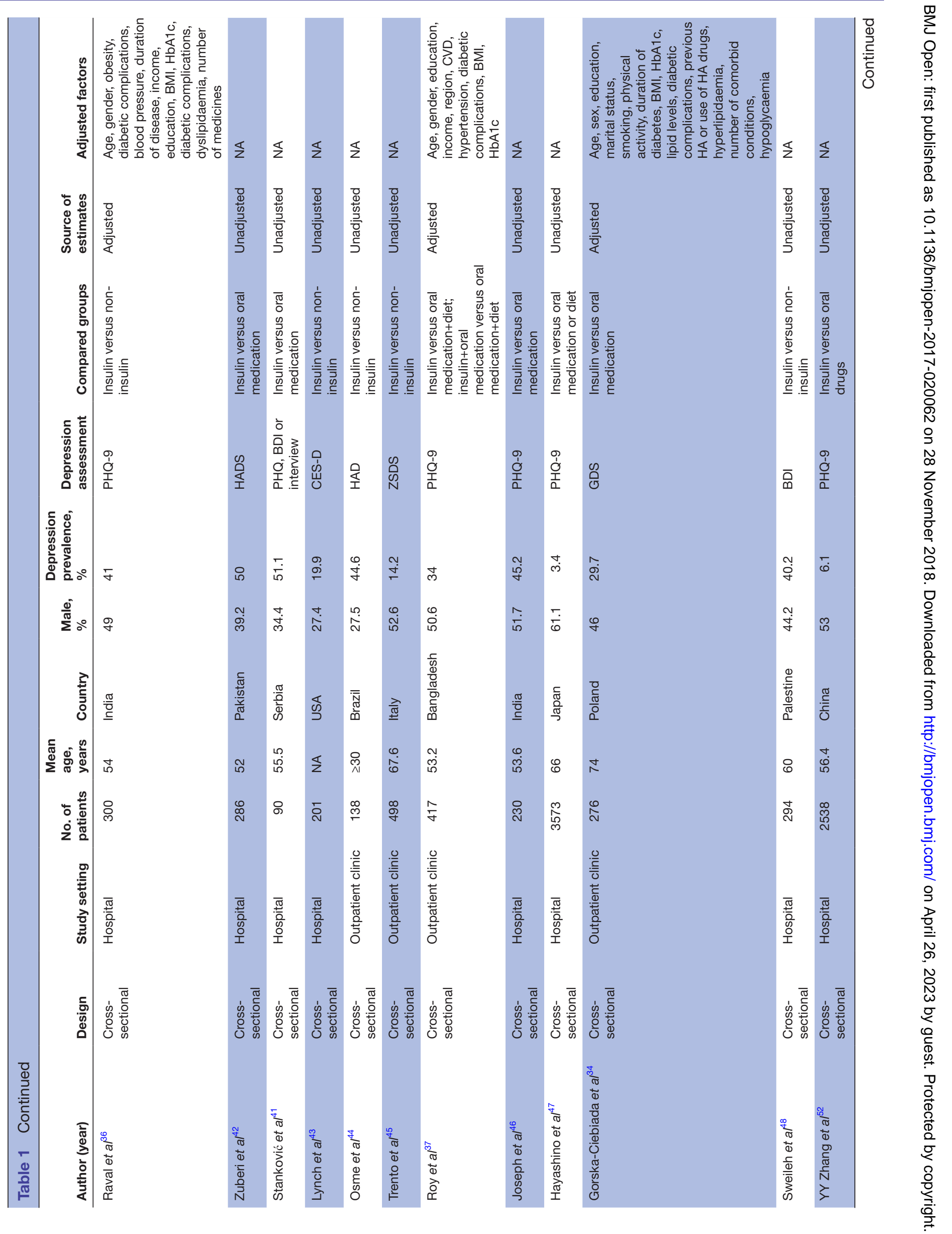




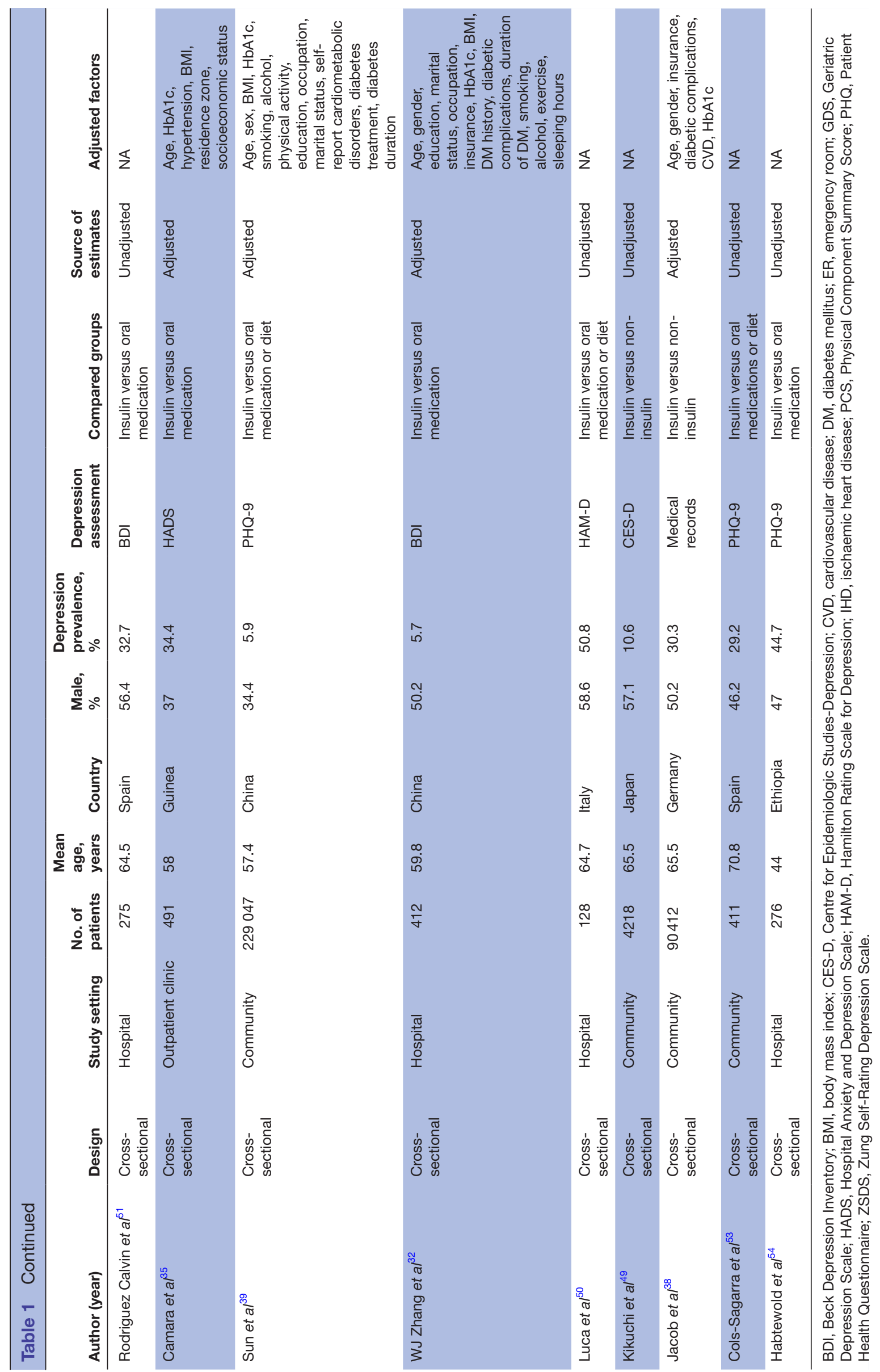




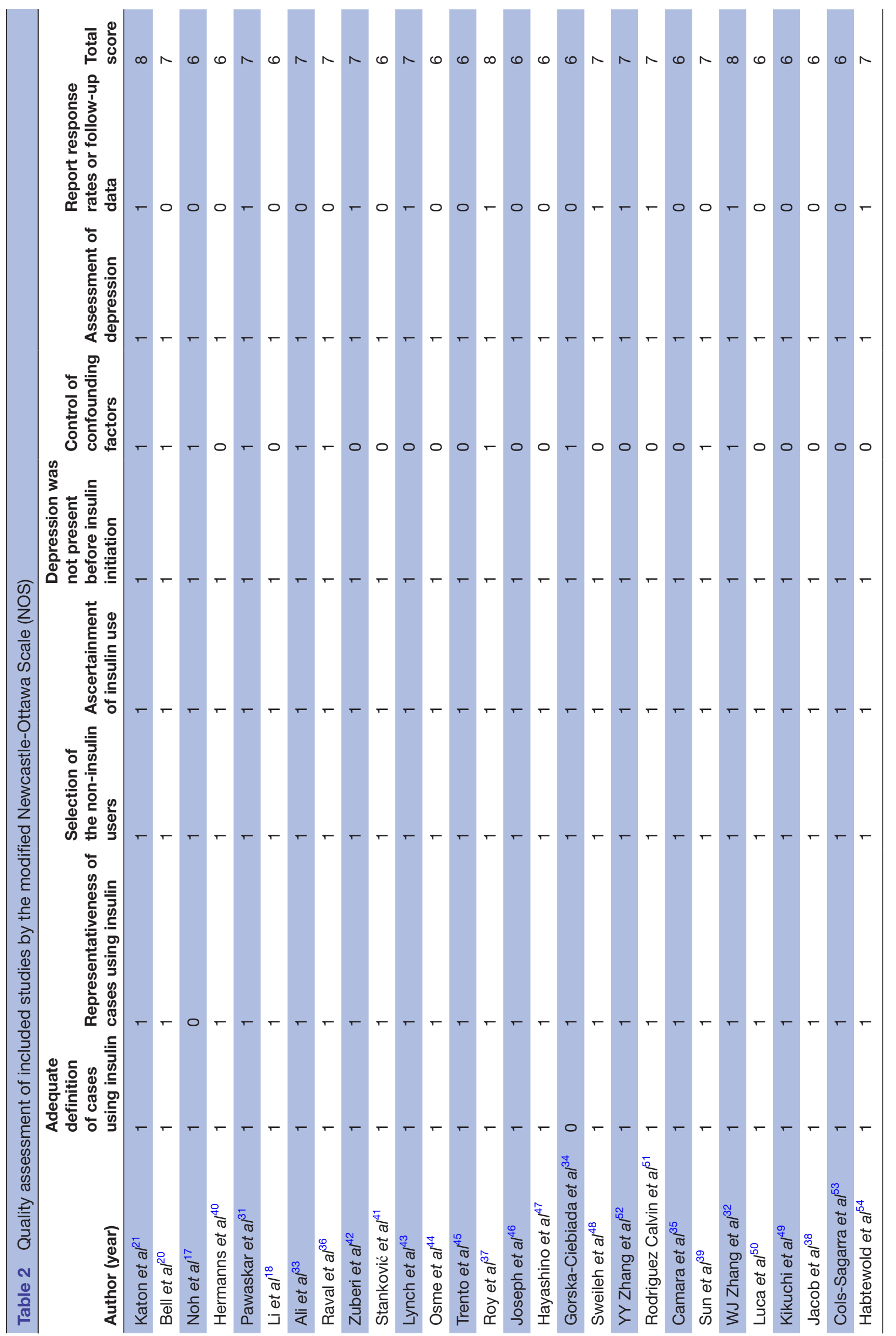

$\stackrel{\infty}{3}$

윰

$\overrightarrow{\vec{A}}$

듬

$\frac{\bar{\sigma}}{\vec{\sigma}}$

क

$\overrightarrow{\vec{\omega}}$

흘. 
Study

ID
$\%$

OR $(95 \% \mathrm{Cl}) \quad$ Weight

\begin{tabular}{|c|c|c|}
\hline Katon et al. (2004) & $1.22(0.83,1.79)$ & 9.60 \\
\hline Bell et al. (2005)a & $0.67(0.37,1.25)$ & 6.73 \\
\hline Bell et al. (2005)b & $0.50(0.20,1.30)$ & 4.01 \\
\hline Noh et al. (2005) & $4.38(1.66,11.60)$ & 3.80 \\
\hline Pawaskar et al. (2007) & $0.88(0.31,2.52)$ & 3.41 \\
\hline Ali et al. (2009) & $1.53(1.17,2.00)$ & 11.23 \\
\hline Raval et al. (2010) & $1.08(0.60,1.95)$ & 6.95 \\
\hline Roy et al. (2012) & $1.20(0.80,2.60)$ & 6.95 \\
\hline Gorska-Ciebiada et al. (2014) & $2.19(1.65,2.92)$ & 11.00 \\
\hline Camara et al. (2015) & $1.53(0.99,2.37)$ & 8.87 \\
\hline Sun et al. (2015) & $2.41(1.58,3.71)$ & 9.01 \\
\hline WJ Zhang et al. (2015) & $1.93(0.99,3.82)$ & 6.04 \\
\hline Jacob et al. (2016) & $1.16(0.98,1.38)$ & 12.42 \\
\hline Overall $($ I-squared $=69.7 \%, p=0.000)$ & $1.41(1.13,1.76)$ & 100.00 \\
\hline NOTE: Weights are from random effects analysis & & \\
\hline .05 & 0 & \\
\hline
\end{tabular}

Figure 2 The pooled adjusted OR for the risk of depression in insulin-prescribed patients compared with those without insulin therapy.

The results of the sensitivity analysis, which was done by excluding studies one by one, might vary when several included studies were excluded (online supplementary figure S1). To identify the sources of heterogeneity, we performed subgroup analyses based on several important confounding factors. Six studies, in particular, compared insulin with oral antidiabetic drugs and showed that insulin therapy was significantly associated with increased risk of depression ( $\mathrm{OR}=1.42,95 \%$ CI 1.08 to $1.86, \mathrm{p}=0.008)$. Two studies that compared insulin with non-drug therapy showed no significant association for insulin and depression $(\mathrm{OR}=0.87,95 \% \mathrm{CI} 0.37$ to $2.03, \mathrm{p}=0.745)$. Additionally, we conducted a subgroup analysis based on the degree of adjustment of confounders, region, identification of depression, sample size, mean age, percentage male and NOS. The association was significant for the subgroups of full adjustment $(+++)$, Asian studies, self-report questionnaires, sample size $\geq 1000$, mean age $<60.0$ years, percentage male $<50.0 \%$, prevalence of depression over $20 \%$ and NOS $<6$ (table 3). Meta-regression analyses indicated a lack of effect measures modification by sample size $(\mathrm{p}=0.93)$, mean age $(\mathrm{p}=0.17)$, percentage male $(\mathrm{p}=0.28)$ or prevalence of depression $(\mathrm{p}=0.75)$.

\section{Meta-analysis of unadjusted results}

Twenty-four studies provided the crude data. All studies were cross-sectional and assessed depression by self-report scales. The studies presented three comparison types (insulin vs non-drug therapy, insulin vs oral antidiabetic drugs, and insulin vs non-insulin treatment). Data that compared insulin and non-insulin therapies were preferred. The pooled results showed that patients with T2DM on insulin therapy were associated with an increased risk of depression compared with those on non-insulin treatment $(\mathrm{OR}=1.59,95 \% \mathrm{CI} 1.41$ to $1.80, \mathrm{p}<0.001)$ (figure 3). The heterogeneity was at a significantly higher level $\left(\mathrm{I}^{2}=59.8 \%, \mathrm{p}<0.001\right)$. Sensitivity analysis revealed no significant variation in the pooled OR by exclusion of any included study (online supplementary figure S2).

Seventeen studies compared insulin with oral antidiabetic drugs and showed a significant association for the risk of depression (OR=1.61, 95\% CI 1.35 to 1.93 , $\mathrm{p}<0.001)$. For six studies that compared insulin use with non-drug treatment, insulin use was associated with an increased risk of depression $(\mathrm{OR}=1.89,95 \% \mathrm{CI} 1.25$ to $2.88, \mathrm{p}=0.002)$. In stratified analyses based on the degree of adjustment of confounders, region, identification of depression, sample size, mean age, percentage male and NOS, there was a significant association between insulin use and depression among all subgroups except in the study conducted in South America (table 4). In meta-regression analyses, sample size $(\mathrm{p}=0.79)$, mean age $(p=0.56)$, percentage male $(p=0.80)$ and the prevalence of depression $(\mathrm{p}=0.68)$ demonstrated no independent effect on the depression outcomes.

\section{Publication bias}

For studies reporting adjusted ORs, the funnel plot was symmetrical (figure 4). No publication bias was shown by Egger's test $(\mathrm{p}=0.94)$ or Begg's test $(\mathrm{p}=0.67)$. For studies presenting crude ORs, the funnel plot was symmetrical (figure 5). We did not detect publication bias by Egger's test $(\mathrm{p}=0.39)$ or Begg's test $(\mathrm{p}=0.94)$.

\section{DISCUSSION}

This is the first meta-analysis that estimated the magnitude of association between insulin therapy and depression. 
Table 3 Subgroup analyses for studies reporting adjusted effect estimates

\begin{tabular}{|c|c|c|c|c|c|c|}
\hline Subgroups & $\begin{array}{l}\text { No. of } \\
\text { studies }\end{array}$ & OR $(95 \% \mathrm{Cl})$ & $P$ value & $1^{2}$ & $\begin{array}{l}\text { P value for } \\
\text { within-stratum } \\
\text { heterogeneity }\end{array}$ & $\begin{array}{l}\text { P value for } \\
\text { between- } \\
\text { stratum } \\
\text { heterogeneity }\end{array}$ \\
\hline \multicolumn{7}{|l|}{ Compared groups } \\
\hline Insulin versus oral drugs & 6 & $1.42(1.08$ to 1.86$)$ & $<0.05$ & $71.3 \%$ & $<0.05$ & 0.28 \\
\hline Insulin versus non-drugs & 2 & 0.87 (0.37 to 2.03$)$ & $>0.05$ & $66.5 \%$ & 0.08 & \\
\hline \multicolumn{7}{|l|}{ Degree of adjustment } \\
\hline+++ & 10 & 1.43 (1.08 to 1.89$)$ & $<0.05$ & $68.9 \%$ & $<0.05$ & 0.44 \\
\hline++ & 2 & 1.24 (0.98 to 1.55$)$ & $>0.05$ & $25.3 \%$ & 0.25 & \\
\hline \multicolumn{7}{|l|}{ Region } \\
\hline USA & 4 & 0.86 (0.57 to 1.31$)$ & $>0.05$ & $36.4 \%$ & 0.19 & 0.12 \\
\hline Asia & 5 & 1.81 (1.18 to 2.79$)$ & $<0.05$ & $59 \%$ & 0.05 & \\
\hline Europe & 2 & 1.58 (0.85 to 2.94$)$ & $>0.05$ & $92.9 \%$ & $<0.05$ & \\
\hline Africa & 1 & 1.53 (0.99 to 2.37 ) & $>0.05$ & - & - & \\
\hline \multicolumn{7}{|l|}{ Identification of depression } \\
\hline Self-report questionnaire & 10 & 1.42 (1.06 to 1.91$)$ & $<0.05$ & $68.9 \%$ & $<0.05$ & 0.69 \\
\hline Medical records & 2 & $1.31(1.00$ to 1.71$)$ & $>0.05$ & $65.6 \%$ & 0.09 & \\
\hline \multicolumn{7}{|l|}{ Sample size } \\
\hline$\geq 1000$ & 4 & 1.46 (1.10 to 1.94$)$ & $<0.05$ & $73.1 \%$ & $<0.05$ & 0.72 \\
\hline$<1000$ & 8 & 1.34 (0.93 to 1.93$)$ & $>0.05$ & $70 \%$ & $<0.05$ & \\
\hline \multicolumn{7}{|l|}{ Mean age, years } \\
\hline$\geq 60.0$ & 5 & 1.12 (0.77 to 1.62$)$ & $>0.05$ & $78.8 \%$ & $<0.05$ & 0.08 \\
\hline$<60.0$ & 6 & 1.74 (1.24 to 2.43$)$ & $<0.05$ & $50.8 \%$ & 0.07 & \\
\hline \multicolumn{7}{|l|}{ Percentage male (\%) } \\
\hline$\geq 50.0$ & 7 & 1.26 (0.97 to 1.63$)$ & $>0.05$ & $62.4 \%$ & $<0.05$ & 0.14 \\
\hline$<50.0$ & 5 & 1.71 (1.25 to 2.35$)$ & $<0.05$ & $53.9 \%$ & 0.07 & \\
\hline \multicolumn{7}{|l|}{ Prevalence of depression } \\
\hline$\geq 20 \%$ & 7 & 1.48 (1.12 to 1.96$)$ & $<0.05$ & $71.3 \%$ & $<0.05$ & 0.53 \\
\hline$<20 \%$ & 5 & 1.25 (0.80 to 1.95$)$ & $>0.05$ & $72.7 \%$ & $<0.05$ & \\
\hline \multicolumn{7}{|l|}{ NOS } \\
\hline 7 or 8 & 8 & 1.25 (0.94 to 1.66$)$ & $>0.05$ & $60.0 \%$ & $<0.05$ & 0.19 \\
\hline$<7$ & 4 & 1.79 (1.14 to 2.80$)$ & $<0.05$ & $84.6 \%$ & $<0.05$ & \\
\hline
\end{tabular}

NOS, Newcastle-Ottawa Scale.

The pooled data of adjusted ORs proved that patients with T2DM on insulin treatment were associated with the prevalence of depressive syndromes compared with those without insulin therapy. When pooling the crude ORs, the results showed a permanent and significant association. We specifically compared insulin use with oral antidiabetic drugs. The adjusted $(\mathrm{OR}=1.42)$ and unadjusted data $(\mathrm{OR}=1.61)$ showed that insulin users were associated to a greater risk of depression.

The source of heterogeneity was explored carefully. In sensitivity analysis, no substantial change in heterogeneity was revealed when excluding any individual study, suggesting homogeneity of the pooled effect estimates. The prevalence of depression could differ based on different ethnicities. ${ }^{55}$ In subgroup analyses of adjusted data, we found significant results for Asian studies. Non-significant results were shown for studies with a sample size below 1000, suggesting that the results were unstable for a small sample size. Substantial change of heterogeneity was also detected for subgroups of insufficient degree of adjustment and depression identified by medical records. However, the number of eligible studies was rather small to draw firm conclusions. For studies with a prevalence of depression below 20\%, substantial change in the effect estimates was observed for adjusted data, and obvious change in heterogeneity for crude data. Thus, this may partly account for the heterogeneity. Finally, significant association was detected if the mean age was $<60.0$ years, percentage male $<50.0 \%$ and NOS $<7$ for adjusted data. This might be because younger patients were associated 


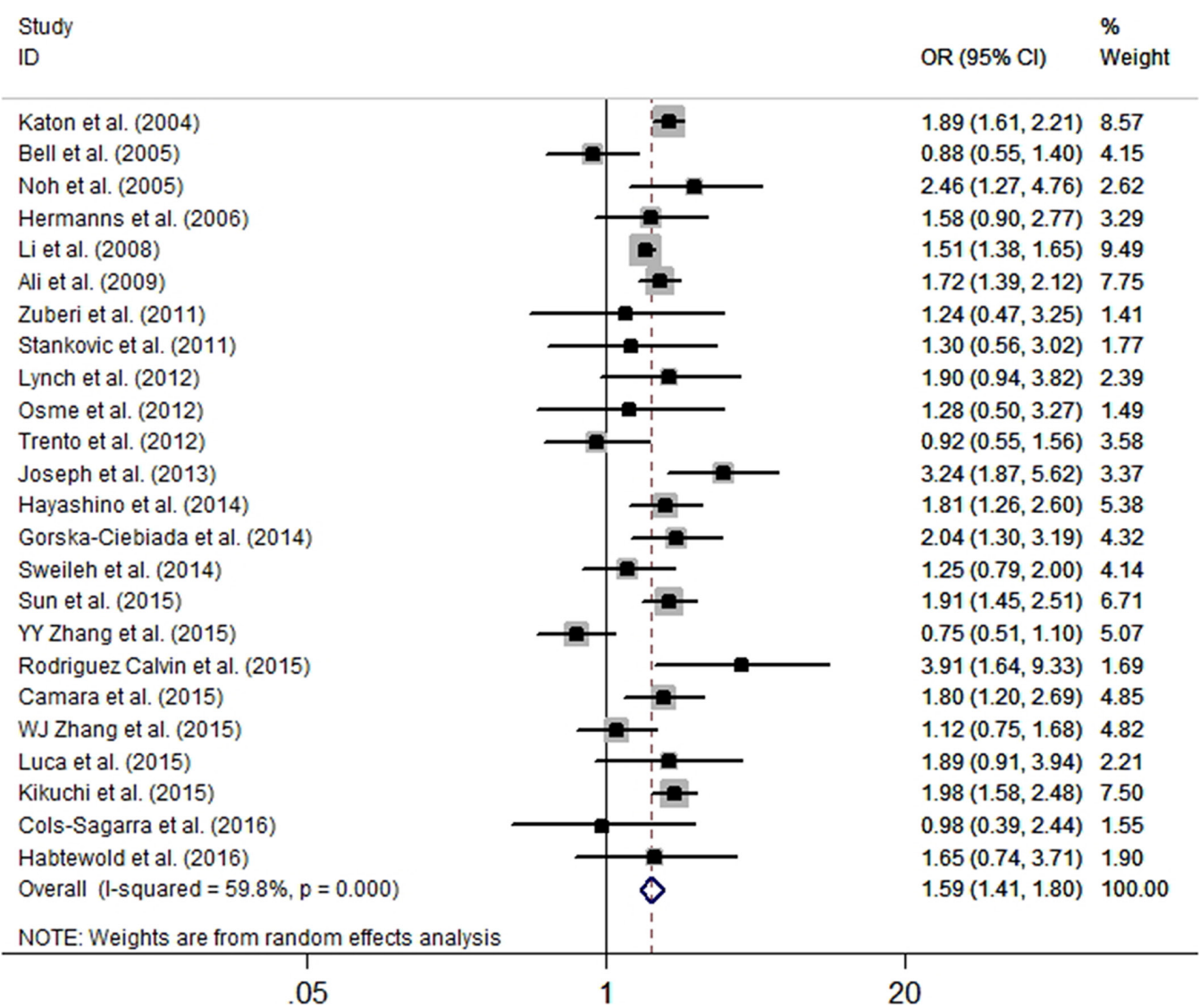

Figure 3 The pooled crude OR for the risk of depression in insulin-prescribed patients compared with those without insulin therapy.

with a higher prevalence of depression, and women receiving insulin therapy might be under greater risk of depression compared with men.

The mechanisms that link diabetes and depression were complex and are still unclear. Depression and T2DM could develop in parallel through shared biological processes. The involved pathways include the innate inflammatory response, the hypothalamic-pituitary-adrenal axis, circadian rhythms and insulin resistance. ${ }^{3}$ Although the overall prevalence of depression is high in patients with diabetes, the Diabetes Education and Self Management for Ongoing and Newly Diagnosed (DESMOND) Trial reported that it was not so in patients with newly diagnosed T2DM. ${ }^{56}$ Screen-detected patients with T2DM showed low distress and anxiety at the time of diagnosis, with a significant increase during the 12-month follow-up period. ${ }^{57}$ In accordance with these findings, we confirmed that insulin therapy was associated with increased prevalence of depression. Patients on insulin therapy had less endogenous insulin and were therefore more susceptible to metabolic dysregulation than patients who might have some residual insulin secretory activity. Especially, patients who are more metabolically labile are more vulnerable to depression. ${ }^{16}$ Besides, insulin therapy is always a symbol of more advanced T2DM. The negative attitude of patients towards insulin therapy may contribute to the delay in insulin initiation, prolonged duration of hyperglycaemia and increased risk of diabetic complications ${ }^{58}$ Psychological insulin resistance has been defined as psychological opposition towards insulin treatment in both patients with diabetes and their prescribers. They may display fear of insulin injection and self-testing, complex regimen, hypoglycaemia and weight gain; a perceived loss of control over one's life; poor self-efficacy concerning insulin treatment; and lack of positive outcomes related to insulin. ${ }^{58-60}$ These psychological aspects may explain the increased risk of depression when insulin was prescribed.

The primary strength of this study was the systematic and expansive search of multiple databases, which minimised the risk of missing data. The meta-analysis identified 28 studies that enrolled participants distributed worldwide. Both the adjusted and crude effect estimates were analysed and demonstrated consistent results. The CIs were narrow, suggesting the precision of pooled results. ${ }^{61}$ For adjusted data, most of the studies had full adjustment for confounders. The subtypes of non-insulin therapy, including oral drug and non-drug treatment, were analysed separately. The between-study heterogeneity was intensively explored by sensitivity, subgroup and meta-regression analyses. Besides, no publication bias was detected among the selected studies.

We were aware of the limitations of this meta-analysis. Our findings mainly relied on cross-sectional data, and as such, the causal and temporal relationship between insulin use and depression could not be established. 
Table 4 Subgroup analyses for studies reporting crude effect estimates

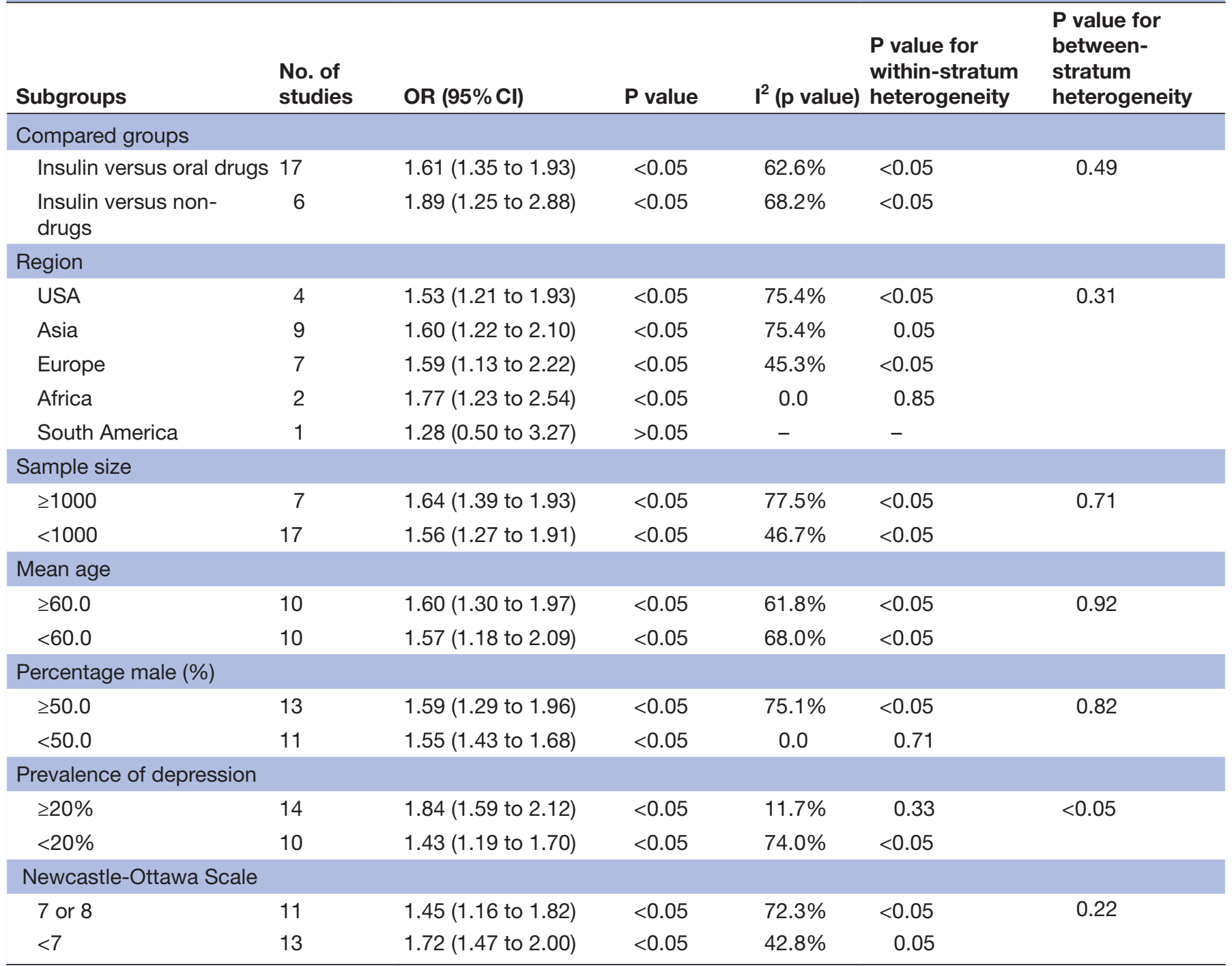

Some studies have a small sample size, which may influence the statistical power. Several studies have reported the response rates. The unmeasured differences between

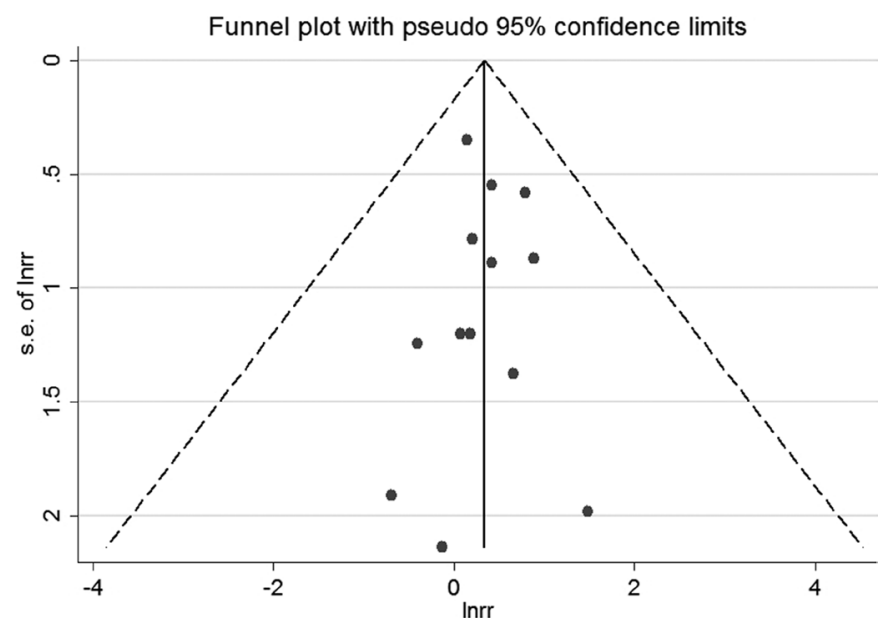

Figure 4 The funnel plot for studies reporting adjusted ORs. s.e. of Inrr, standard error of Inrr. respondents and non-respondents may potentially influence the pooled results. Most of the studies used self-reported scales rather than clinical interview-based

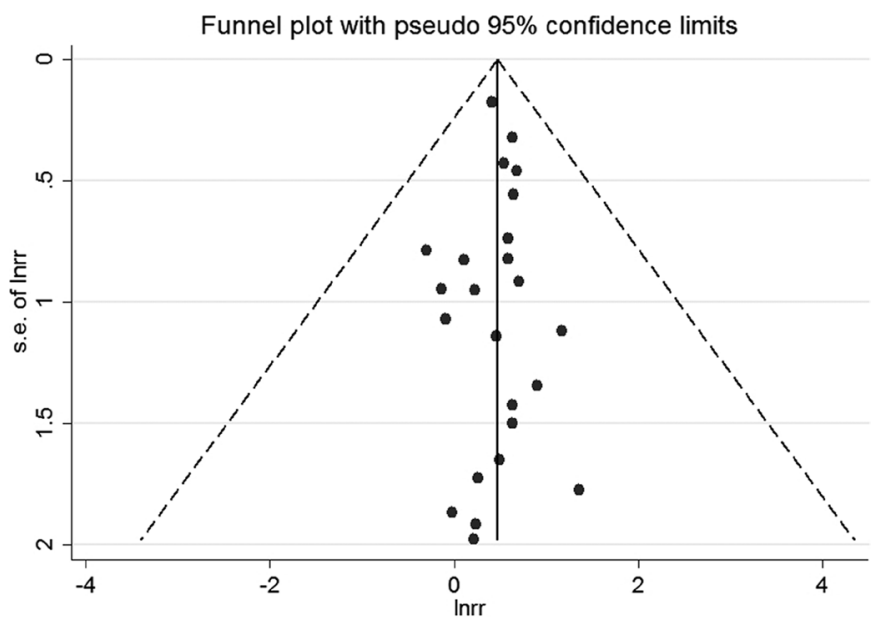

Figure 5 The funnel plot for studies presenting crude ORs. 
assessments to identify depression. Prevalence of depression was generally much higher using the self-reported scales than standardised diagnostic interviews. ${ }^{2062}$ Furthermore, the findings of insulin therapy versus specific oral drugs and the prevalence of depression were not illustrated due to inclusion of less number of studies in each subset. Moreover, background oral antidiabetic drug uses in the insulin group might affect the association of insulin use with the risk of depressive syndromes, although this information was not available in most of the included studies. In addition, although subgroup analyses based on several factors were conducted, substantial residual heterogeneity was observed in numerous subsets. These results were restricted due to uncontrolled baseline characteristics of included patients and studies. Finally, the impact of the total number of daily insulin injections with depression development was included only in a few studies, and these presented as potential confounders in patients who received insulin therapy and with progression of depression.

\section{CONCLUSIONS}

In conclusion, patients with T2DM who were prescribed insulin were associated with depressive syndromes. For insulin users, careful monitoring of depressive symptoms should be incorporated in the management of the disease. Intensified psychological and education programmes should be carried out to prevent depressive illness after insulin initiation in primary care settings.

Contributors XB contributed to study concepts, manuscript preparation, literature research and drafting the manuscript. ZLi, ZLiu and DY carried out literature research and data analysis, and revised the manuscript for important content. All authors read and approved the final manuscript.

Funding The authors have not declared a specific grant for this research from any funding agency in the public, commercial or not-for-profit sectors.

Competing interests None declared.

Patient consent Not required.

Provenance and peer review Not commissioned; externally peer reviewed.

Data sharing statement No additional data are available.

Open access This is an open access article distributed in accordance with the Creative Commons Attribution Non Commercial (CC BY-NC 4.0) license, which permits others to distribute, remix, adapt, build upon this work non-commercially, and license their derivative works on different terms, provided the original work is properly cited, appropriate credit is given, any changes made indicated, and the use is non-commercial. See: http://creativecommons.org/licenses/by-nc/4.0/.

\section{REFERENCES}

1. Tabák AG, Akbaraly TN, Batty GD, et al. Depression and type 2 diabetes: a causal association? Lancet Diabetes Endocrinol 2014;2:236-45.

2. Type 2 Diabetes in Adults: Management. National Institute for Health and Care Excellence: Clinical Guidelines. London, 2015.

3. Moulton CD, Pickup JC, Ismail K. The link between depression and diabetes: the search for shared mechanisms. Lancet Diabetes Endocrinol 2015;3:461-71.

4. Mezuk B, Eaton WW, Albrecht S, et al. Depression and type 2 diabetes over the lifespan: a meta-analysis. Diabetes Care 2008;31:2383-90.
5. Nouwen A, Winkley K, Twisk J, et al. Type 2 diabetes mellitus as a risk factor for the onset of depression: a systematic review and metaanalysis. Diabetologia 2010;53:2480-6.

6. van Dooren FE, Nefs G, Schram MT, et al. Depression and risk of mortality in people with diabetes mellitus: a systematic review and meta-analysis. PLoS One 2013;8:e57058.

7. Kan C, Silva N, Golden SH, et al. A systematic review and metaanalysis of the association between depression and insulin resistance. Diabetes Care 2013;36:480-9.

8. Ismail-Beigi F. Clinical practice. Glycemic management of type 2 diabetes mellitus. N Engl J Med 2012;366:1319-27.

9. Ohn JH, Kwak SH, Cho YM, et al. 10-year trajectory of $\beta$-cell function and insulin sensitivity in the development of type 2 diabetes: a community-based prospective cohort study. Lancet Diabetes Endocrinol 2016;4:27-34

10. Cahn A, Miccoli R, Dardano A, et al. New forms of insulin and insulin therapies for the treatment of type 2 diabetes. Lancet Diabetes Endocrinol 2015;3:638-52.

11. Home P, Riddle M, Cefalu WT, et al. Insulin therapy in people with type 2 diabetes: opportunities and challenges? Diabetes Care 2014;37:1499-508

12. Weng J, Li Y, Xu W, et al. Effect of intensive insulin therapy on betacell function and glycaemic control in patients with newly diagnosed type 2 diabetes: a multicentre randomised parallel-group trial. Lancet 2008;371:1753-60.

13. Kramer CK, Zinman B, Retnakaran R. Short-term intensive insulin therapy in type 2 diabetes mellitus: a systematic review and metaanalysis. Lancet Diabetes Endocrinol 2013;1:28-34.

14. Holman RR, Paul SK, Bethel MA, et al. 10-year follow-up of intensive glucose control in type 2 diabetes. N Engl J Med 2008;359:1577-89.

15. Holmes-Truscott E, Skinner TC, Pouwer F, et al. Explaining psychological insulin resistance in adults with non-insulin-treated type 2 diabetes: The roles of diabetes distress and current medication concerns. Results from Diabetes MILES-Australia. Prim Care Diabetes 2016;10:75-82.

16. Surwit RS, van Tilburg MA, Parekh PI, et al. Treatment regimen determines the relationship between depression and glycemic control. Diabetes Res Clin Pract 2005;69:78-80.

17. Noh JH, Park JK, Lee HJ, et al. Depressive symptoms of type 2 diabetics treated with insulin compared to diabetics taking oral anti-diabetic drugs: a Korean study. Diabetes Res Clin Pract 2005;69:243-8.

18. Li C, Ford ES, Strine TW, et al. Prevalence of depression among U.S. adults with diabetes: findings from the 2006 behavioral risk factor surveillance system. Diabetes Care 2008;31:105-7.

19. Al-Amer RM, Sobeh MM, Zayed AA, et al. Depression among adults with diabetes in Jordan: risk factors and relationship to blood sugar control. J Diabetes Complications 2011;25:247-52.

20. Bell RA, Smith SL, Arcury TA, et al. Prevalence and correlates of depressive symptoms among rural older African Americans, Native Americans, and whites with diabetes. Diabetes Care 2005;28:823-9.

21. Katon W, von Korff M, Ciechanowski P, et al. Behavioral and clinical factors associated with depression among individuals with diabetes. Diabetes Care 2004;27:914-20.

22. Mikailiūkštienė A, Juozulynas A, Narkauskaite L, et al. Quality of life in relation to social and disease factors in patients with type 2 diabetes in Lithuania. Med Sci Monit 2013;19:165-74.

23. Stroup DF, Berlin JA, Morton SC, et al. Meta-analysis of observational studies in epidemiology: a proposal for reporting. Meta-analysis Of Observational Studies in Epidemiology (MOOSE) group. JAMA 2000;283:2008-12.

24. Smarr KL, Keefer AL. Measures of depression and depressive symptoms: Beck Depression Inventory-II (BDI-II), Center for Epidemiologic Studies Depression Scale (CES-D), Geriatric Depression Scale (GDS), Hospital Anxiety and Depression Scale (HADS), and Patient Health Questionnaire-9 (PHQ-9). Arthritis Care Res 2011;63(Suppl 11):S454-S466.

25. Organization WH. The ICD-10 classification of mental and behavioural disorders: clinical descriptions and diagnostic guidelines. Geneva: World Health Organization, 1992.

26. Association D-AP. Diagnostic and statistical manual of mental disorders. Arlington: American Psychiatric Publishing, 2013.

27. Wells GA, Shea B, Oc D. The Newcastle-Ottawa Scale (NOS) for assessing the quality of nonrandomised studies in meta-analyses. 2008. http://wwwohrica/programs/clinical_epidemiology/oxfordasp (accessed 27 Apr 2016).

28. Higgins JP, Thompson SG, Deeks JJ, et al. Measuring inconsistency in meta-analyses. BMJ 2003;327:557-60.

29. Begg CB, Mazumdar M. Operating characteristics of a rank correlation test for publication bias. Biometrics 1994;50:1088-101. 
30. Egger M, Davey Smith G, Schneider M, et al. Bias in meta-analysis detected by a simple, graphical test. BMJ 1997;315:629-34.

31. Pawaskar MD, Anderson RT, Balkrishnan R. Self-reported predictors of depressive symptomatology in an elderly population with type 2 diabetes mellitus: a prospective cohort study. Health Qual Life Outcomes 2007;5:50.

32. Zhang $\mathrm{W}, \mathrm{Xu} \mathrm{H}$, Zhao $\mathrm{S}$, et al. Prevalence and influencing factors of co-morbid depression in patients with type 2 diabetes mellitus: a General Hospital based study. Diabetol Metab Syndr 2015;7:60.

33. Ali S, Davies MJ, Taub NA, et al. Prevalence of diagnosed depression in South Asian and white European people with type 1 and type 2 diabetes mellitus in a UK secondary care population. Postgrad Med $J$ 2009;85:238-43.

34. Gorska-Ciebiada M, Saryusz-Wolska M, Ciebiada M, et al. Mild cognitive impairment and depressive symptoms in elderly patients with diabetes: prevalence, risk factors, and comorbidity. J Diabetes Res 2014;2014:1-7.

35. Camara A, Baldé NM, Enoru S, et al. Prevalence of anxiety and depression among diabetic African patients in Guinea: association with $\mathrm{HbA1c}$ levels. Diabetes Metab 2015;41:62-8.

36. Raval A, Dhanaraj E, Bhansali A, et al. Prevalence and determinants of depression in type 2 diabetes patients in a tertiary care centre. Indian J Med Res 2010;132:195-200.

37. Roy T, Lloyd CE, Parvin M, et al. Prevalence of co-morbid depression in out-patients with type 2 diabetes mellitus in Bangladesh. BMC Psychiatry 2012;12:123.

38. Jacob L, Kostev K. Prevalence of depression in type 2 diabetes patients in German primary care practices. J Diabetes Complications 2016;30:432-7.

39. Sun JC, Xu M, Lu JL, Jl L, et al. Associations of depression with impaired glucose regulation, newly diagnosed diabetes and previously diagnosed diabetes in Chinese adults. Diabet Med 2015;32:935-43.

40. Hermanns N, Kulzer B, Krichbaum M, et al. How to screen for depression and emotional problems in patients with diabetes: comparison of screening characteristics of depression questionnaires, measurement of diabetes-specific emotional problems and standard clinical assessment. Diabetologia 2006;49:469-77.

41. Stanković Z, Jašović-Gašić $M$, Zamaklar M. Psycho-social and clinical variables associated with depression in patients with type 2 diabetes. Psychiatr Danub 2011;23:34-44.

42. Zuberi SI, Syed EU, Bhatti JA. Association of depression with treatment outcomes in Type 2 Diabetes Mellitus: a cross-sectional study from Karachi, Pakistan. BMC Psychiatry 2011;11:27.

43. Lynch CP, Hernandez-Tejada MA, Strom JL, et al. Association between spirituality and depression in adults with type 2 diabetes. Diabetes Educ 2012;38:427-35.

44. Osme SF, Ferreira L, Jorge MT, et al. Difference between the prevalence of symptoms of depression and anxiety in non-diabetic smokers and in patients with type 2 diabetes with and without nicotine dependence. Diabetol Metab Syndr 2012;4:39.

45. Trento M, Raballo M, Trevisan M, et al. A cross-sectional survey of depression, anxiety, and cognitive function in patients with type 2 diabetes. Acta Diabetol 2012;49:199-203.

46. Joseph N, Unnikrishnan B, Raghavendra Babu YP, et al. Proportion of depression and its determinants among type 2 diabetes mellitus patients in various tertiary care hospitals in Mangalore city of South India. Indian J Endocrinol Metab 2013;17:681-8.

47. Hayashino Y, Mashitani T, Tsujii S, et al. Elevated levels of hs-CRP are associated with high prevalence of depression in japanese patients with type 2 diabetes: the Diabetes Distress and Care Registry at Tenri (DDCRT 6). Diabetes Care 2014;37:2459-65.

48. Sweileh WM, Abu-Hadeed HM, Al-Jabi SW, et al. Prevalence of depression among people with type 2 diabetes mellitus: a cross sectional study in Palestine. BMC Public Health 2014;14:163.

49. Kikuchi $\mathrm{Y}$, Iwase M, Fujii $\mathrm{H}$, et al. Association of severe hypoglycemia with depressive symptoms in patients with type 2 diabetes: the Fukuoka Diabetes Registry. BMJ Open Diabetes Res Care 2015;3:e000063.

50. Luca A, Luca M, Di Mauro M, et al. Alexithymia, more than depression, influences glycaemic control of type 2 diabetic patients. $J$ Endocrinol Invest 2015;38:653-60.

51. Rodríguez Calvín JL, Zapatero Gaviria A, Martín Ríos MD. Prevalence of depression in type 2 diabetes mellitus. Revista Clínica Española 2015;215:156-64.

52. Zhang Y, Ting RZ, Yang W, et al. Depression in Chinese patients with type 2 diabetes: associations with hyperglycemia, hypoglycemia, and poor treatment adherence. J Diabetes 2015;7:800-8.

53. Cols-Sagarra C, López-Simarro $\mathrm{F}$, Alonso-Fernández $\mathrm{M}$, et al. Prevalence of depression in patients with type 2 diabetes attended in primary care in Spain. Prim Care Diabetes 2016;10:369-75

54. Habtewold TD, Alemu SM, Haile YG. Sociodemographic, clinical, and psychosocial factors associated with depression among type 2 diabetic outpatients in Black Lion General Specialized Hospital, Addis Ababa, Ethiopia: a cross-sectional study. BMC Psychiatry 2016;16:103

55. Harris PA. The impact of age, gender, race, and ethnicity on the diagnosis and treatment of depression. J Manag Care Pharm 2004;10:S2-7.

56. Skinner TC, Carey ME, Cradock $S$, et al. Depressive symptoms in the first year from diagnosis of Type 2 diabetes: results from the DESMOND trial. Diabet Med 2010;27:965-7.

57. Thoolen BJ, de Ridder DT, Bensing JM, et al. Psychological outcomes of patients with screen-detected type 2 diabetes: the influence of time since diagnosis and treatment intensity. Diabetes Care 2006;29:2257-62.

58. Petrak F, Stridde E, Leverkus F, et al. Development and validation of a new measure to evaluate psychological resistance to insulin treatment. Diabetes Care 2007;30:2199-204.

59. Brod M, Kongsø JH, Lessard S, et al. Psychological insulin resistance: patient beliefs and implications for diabetes management. Qual Life Res 2009;18:23-32.

60. Polonsky WH, Hajos TR, Dain MP, et al. Are patients with type 2 diabetes reluctant to start insulin therapy? An examination of the scope and underpinnings of psychological insulin resistance in a large, international population. Curr Med Res Opin 2011;27:1169-74.

61. Guyatt GH, Oxman AD, Kunz R, et al. GRADE guidelines 6 . Rating the quality of evidence-imprecision. J Clin Epidemiol 2011;64:1283-93.

62. Anderson RJ, Freedland KE, Clouse RE, et al. The prevalence of comorbid depression in adults with diabetes: a meta-analysis. Diabetes Care 2001;24:1069-78. 